2016-07

\title{
Models and activities of critical care outreach in New Zealand hospitals: results of a national census.
}

\section{Pedersen, A}

http://hdl.handle.net/10026.1/13048

\section{$10.1111 /$ nicc. 12080}

Nurs Crit Care

All content in PEARL is protected by copyright law. Author manuscripts are made available in accordance with publisher policies. Please cite only the published version using the details provided on the item record or document. In the absence of an open licence (e.g. Creative Commons), permissions for further reuse of content should be sought from the publisher or author. 
Pedersen A, Psirides A Coombs MA. 2014. Models and activities of critical care outreach in New Zealand hospitals: results of a national census. Nursing in Critical Care 2016, 21, 4, 233-242

Author copy. Accepted $6^{\text {th }}$ December 2013. First published: 19 February 2014. DOI. $10.1111 /$ nicc. 12080

Title Page

Title

MODELS AND ACTIVITIES OF CRITICAL CARE OUTREACH IN NEW ZEALAND

HOSPITALS: results of a national census

Corresponding Author

Anne Pedersen

Intensive Care Services

Wellington Regional Hospital

Riddiford Street, Newtown

Wellington

New Zealand

6018

Telephone: 0064221560437 (mobile)

Fax: 006448060440

Email: anne.pedersen@ccdhb.org.nz

$\mathrm{MN}$ (Clinical), BNurs (Hons), RN

Clinical Nurse Specialist Patient at Risk Service

Authors

Maureen Coombs

Professor of Clinical Nursing

Graduate School of Nursing Midwifery and Health

Victoria University

And

Capital and Coast District Health Board, Wellington 
New Zealand

$\mathrm{MBE}, \mathrm{PhD}, \mathrm{RN}$

Alex Psirides

Intensive Care Specialist

Intensive Care Unit

Capital and Coast District Health Board, Wellington

New Zealand

$\mathrm{MB}, \mathrm{BS}, \mathrm{BSC}$ (Hons), FCICM

\section{Abstract}

Aim: To review the clinical models and activities of critical care outreach (CCO) in acute care New Zealand (NZ) public hospitals.

Methods: A two-stage data collection process was used to inform this study. Stage 1 occurred in 2012 when a cross-sectional descriptive online survey was distributed to the nurse managers of all CCO in (NZ). In Stage 2 (2013) all respondent sites were contacted again to obtain copy of outreach documentation including daily handover sheet, snap shot of clinical databases, and activity reports for hospital service managers for analysis.

Results: Twenty acute care public hospitals replied to the census request (100\%). Nine hospitals (45\%) had a CCO and fully completed the survey. Reflecting the geographical distribution of acute care public hospitals in NZ, CCO were mostly located in the North Island (89\%). There was considerable diversity in the models of CCO used. All 9 hospitals had CCO that were nurse-led and $66 \%$ of these had various levels of intensive care medical input. In addition, 2 sites (10\%) had a formalised Medical Emergency Team (MET) system that complemented the nurse-led CCO. There was variation in the size and scope of each CCO with only 4 of the nine sites providing 24-hour clinical cover across the week. The majority of referral requests made to CCO were for ward-based reviews (mean 57\%, range $27-80 \%$ ) and intensive care discharge reviews (31\%). The most frequently performed CCO activities across 
the sample were: provision of support to ward staff (89\%); physical assessment and direct clinical support to patients (78\%); and advice/intervention in support of the primary team (78\%). All CCO routinely collected data on activity across a wide range of clinical and service activity areas. There was no evidence of regional or national data reporting.

Conclusion: Less than half of public acute care hospitals in NZ have an established CCO, despite national recommendations calling for the establishment of a service to support acutely unwell ward patients in every hospital. NZ hospitals that have CCO have adopted recognised international models of RRT and adapted these to meet local demands within the available resource. Whilst the evidence base demonstrating impact of CCO continues to be established, international support for CCO continues. Given this, CCO should be more widely available 27/4 and activities standardized across NZ to align with best practice.

Keywords (CINAHL headings where possible) Rapid response systems, critical care outreach 


\section{Introduction}

Much has been written over the past 10 years of the increasing acuity within hospitals, corresponding with higher demand for critical care expertise outside of the intensive care unit (Coombs and Dillon, 2002; Hillman et al., 2005; Steel and Reynolds, 2008; Jones et al., 2011; Jones et al., 2013). To address this increasing need, a range of clinical response systems have been implemented internationally. These are collectively referred to as rapid response systems (RRS) and are now a recognised part of hospital-wide surveillance systems targeting and intervening to help physiologically unstable patients in acute care wards (Jones et al., 2011).

\section{Models of rapid response systems}

RRS are designed to improve the safety of deteriorating hospital patients through recognition of high-risk patients, early notification and review by a response team, and ongoing evaluation of the system's performance (Howell and Stevens, 2013). RRS has two key features: an afferent limb (to detect patient deterioration and trigger a response) often through use of early warning systems (EWS), and an efferent limb (the response team). Within the literature several terms are used to describe the efferent limb of the system. These include: rapid response teams (DeVita et al., 2006), critical care outreach (Donahue and Endacott, 2010), medical emergency teams (Hillman et al., 2001), and in recent years the Intensive Care Unit liaison nurse (ICULN) (Eliott et al., 2012). With such a proliferation of approaches within the efferent limb, there is often crossover of how RRT and CCO is used.

Rapid response teams (RRT) have been described as a clinical team that is activated to respond to the acutely unwell ward patient (Pringle et al., 2011). RRT assess patients with developing respiratory, cardiac or neurological deterioration; at an earlier juncture than traditional cardiac arrest teams who intervene once patients develop respiratory or cardiac arrest (Howell and Stevens, 2013). Although RRT are predominantly nurse-led, there are variations of RRT, with some described as being either physician or nurse-led (Resuscitation Central, 2013) with interdisciplinary models also described (Howell and Stevens, 2013). Medical emergency teams (MET) are physician-led teams that can initiate intensive care level support at the patient's bedside, often through advanced airway support and intravenous management (Pringle et al., 2011). Critical care outreach (CCO) teams are nurse-led and share similarities with many aspects of RRT. CCO also focus on providing education and training to ward staff and support patients and their families immediately after discharge from a critical care area (Salt, 2013). Such proliferation in service models 
has resulted from high level international health policies supporting initiatives for the unwell ward patient (Department of Heath (DoH), 2005; Australian commission on Safety and Quality in Health Care (ACSQHC), 2011).

Whilst this worldwide concern to address the needs of deteriorating ward patients is clear (Buist et al., 2007), demonstrating the effectiveness of RRS has been more problematic (Jones et al., 2011). For example, a complex and detailed evaluation of all CCO in England by the Intensive Care and National Audit and Research Centre found a range of CCO models had developed in response to local need (Rowan et al., 2008). Within the ICNARC evaluation a systematic review of 23 studies exploring impact of CCO activity concluded that even though there was some evidence of improved patient outcomes, but this was not robust (Esmonde et al., 2006). This study supported previous findings on the absence of mortality and morbidity data (Chan et al., 2010; Winters et al., 2007). However empirical evidence demonstrates some impact of CCO. Esmonde et al., 2006) noted a significant decrease in cardiopulmonary resuscitation rates preceding ICU admission and a reduction in afterhours admissions to ICU after the introduction of CCO. A second systematic review of 34 studies conducted in the United States (18 considered high-quality) evaluated the effectiveness and implementation of RRS in acute care settings (Winters et al., 2013). This review concluded that RRS were associated with reduced rates of cardiorespiratory arrest outside of intensive care units and reduced hospital mortality. Similarly, single centre studies in Australia have demonstrated that MET calls reduce patient mortality, reduce ICU readmission rates and decrease the incidence of cardiac arrests (Bellomo et al., 2003; Jones et al., 2005; Buist et al., 2007).

Whilst such diverse models of RRS have developed internationally from the late 1990s, most RRS initiatives in NZ were developed much later. Similar to other countries, the NZ response came after an independent advisory body advised hospitals to implement a system of care to identify and respond early to physiologically unstable patients (Health and Disability Commissioner (HDC), 2007). Literature to date in the NZ setting appears to demonstrate a preference for the CCO model (Pirret, 2008; Salt, 2013). Therefore for the purposes of this paper, CCO will be used to describe the rapid response model used in the NZ context.

Whilst there is a growing body of international literature describing and evaluating CCO, there is little NZ data published (Psirides et al., 2013). This study seeks to 
address this gap through describing the characteristics and service provision of CCO in NZ.

\section{Methods}

\section{Aim}

The aim of this study was to explore current models and activities of CCO within acute care public hospitals in NZ. This study was undertaken in two stages using a cross sectional survey design and content analysis of clinical data reports from each RRS. Stage 1 consisted of a descriptive online survey adapted from an existing survey instrument previously used to describe the provision of critical CCO in England (McDonnell et. al, 2007). In Stage 2, outreach documentation including daily handover sheet, snap shot of clinical databases, and activity reports for hospital service managers were obtained, collated and analysed.

\section{Sampling}

Non-probability sampling was undertaken. All the clinical nurse managers of intensive care and known CCO representatives from each public hospital were identified through existing professional networks. The sample consisted of all tertiary, metropolitan and regional hospitals $(n=20)$. Rural hospitals in NZ were not included $(n=18)$ as these do not support CCO in NZ. Initial contact with potential hospital sites was undertaken verbally with follow-on email confirmation. In hospitals where it was unclear whether a CCO existed, the Charge Nurse Manager of each ICU or High Dependency Unit (HDU) was contacted by telephone and with a follow-on email and invited to participate in the study.

\section{Data collection tool}

The survey tool, adapted for this study, was originally used to describe the development, introduction, implementation and models of English CCO (McDonnell et al., 2007). Permission was gained from the author of the original English survey tool for its adaptation and use in NZ (personal correspondence). The survey tool was adapted to elicit the number, structure, function and activity of all CCO in NZ (Table 1).

The survey tool was assessed for NZ context with a pilot group of CCO nurses ( $n=15)$. The tool was examined for face and content validity (Rattray, 2007). The group reviewed the draft survey questions and commented on the survey's ability to meet the study aim, the comprehensiveness of the survey questions, and any potential difficulties in respondents completing the survey tool. In total, four sections from 
the original English survey were excluded from the NZ survey. Of these, two contained questions specific to the English National Health Service (NHS) system, and were therefore not applicable to the healthcare context in NZ. Two others were specific to the type of 'track and trigger' systems used, which has already been reported in another NZ study (Psirides et al., 2013). Fourteen sections of the original survey were left unchanged. One question was added to determine the nature of any patient safety-related initiatives that CCO were involved with. The survey questions used in the final NZ tool were predominantly closed questions, with optional free text boxes to capture any additional qualitative comments. Topics covered in the survey are presented in Table 1.

INSERT TABLE 1

\section{Data Collection}

Data collection occurred in two stages over a seven month period (September 2012 to March 2013).

\section{Stage 1}

Intensive care units and contacts were identified as described above (See 2.2

Sampling). An initial email was sent to the identified contacts at all acute care public hospitals $(n=20)$ explaining the study aims and inviting them to participate in the national census via an electronic link to an online survey tool (SurveyMonkey). Whilst individual respondents were anonymous, sites were identifiable due to the small sample size. If a CCO was not established, responders to the initial contact email were asked to send a reply clearly indicating that the hospital did not have a CCO. Two email reminders were sent out to the sample over a six week period.

\section{Stage 2}

The second stage of the data collection occurred through further email requests to all participating hospitals with CCO requesting electronic or hard copies of outreach documentation including daily handover sheet, snap shot of clinical databases, and activity reports for hospital service managers. The purpose of collecting this documentation was to identify the type of data collated, how this data was collected and the type and service activity of the CCO.

\section{Data analysis}

Discrete data analysis strategies were used for the two stages. Due to the small sample size, survey data was manually processed and analysed. Descriptive 
statistical techniques were used to summarise and describe characteristics of the data by measuring variability, mean and percentages. Data from the free text boxes was collated and analysed. The clinical documents obtained in Stage 2 were collated and analysed to understand what CCO data was collected and how and who this was being reported on. In order to make sense of the data, a content analysis approach was undertaken whereby data was organised into categories (Elo and Kyngäs, 2008) to describe and quantify $\mathrm{CCO}$ activities and reporting. In this way, the documents gave context to the environment that CCO operated in, provided supplementary research data, and acted as a source of data triangulation (Bowen, 2009).

\section{Ethical Considerations}

Information about the study and the reporting and dissemination of findings were detailed in the contact email. It was stated that consent was implied by return of the completed census. All returned survey responses, and the resultant data were stored securely and only accessible by the study investigators.

The main ethical challenge in this study was related to the small number of public hospitals in NZ. Ethical advice was sought from the Health and Disability Ethics Committee (HDEC) in NZ. After full submission and consideration by the HDEC, reply was received that formal ethical approval from the HDEC was not required (Reference: 12/CEN/14). To minimise the risk of identification and maintain anonymity, no patient or site specific identifying details were reported on and only aggregated data was used.

\section{Results}

There was $100 \%$ response rate from all hospitals to the initial request for information. Nine sites reported having a CCO and were therefore eligible to complete the online survey, and eight of these sites provided evidence of the types of data their CCO collected. The results of the survey are presented under five sections: CCO and hospital characteristics; roles and functions of CCO; staffing and workforce; clinical delivery of care; data collected by CCO. Twenty comments were received in the free text boxes. The majority of these comments helped to contextualize the responses made in the survey; these are not reported on here.

\section{CCO and hospital characteristics}

Table 2 describes the hospital and CCO characteristics. Less than half $(n=9)$ respondents reported that their hospital had a CCO. Of the eleven sites (55\%) without CCO, five reported limited financial resources that impacted on the setting 
up of CCO with four hospitals not perceiving the need for CCO. Of the nine hospitals with CCO, eight (89\%) of these hospitals had general ICUs combined with a number of funded high dependency unit (HDU) beds.

\section{INSERT TABLE 2}

Results from the survey demonstrated that NZ's first CCO was established in 1995, with an increased growth in CCO in the late 2000's as illustrated in Figure 1. As demonstrated the peak year for establishment of RRS was 2008.

\section{INSERT FIGURE 1}

\section{Roles and functions of CCO}

There was significant variation in service configuration and therefore roles of the CCO. A range of titles were held by practitioners in each CCO, such as Clinical Nurse Advisor, Clinical Resource Nurse, Patient at Risk Nurse $(n=2)$, ICU Outreach Nurse $(n=2)$, Rapid Response Team and Critical Care Outreach Nurse.

One of the larger tertiary hospitals had three components of CCO: a critical care nurse-led service that followed-up ICU discharges; a second team (non-ICU) that attended clinical emergencies and a third team, located in the national paediatric hospital site, that followed up paediatric emergencies and referrals only.

Two hospitals had a MET linked with the CCO and an EWS escalation pathway. MET calls accounted for $16-22 \%$ of referral calls to CCO in these sites. Five hospitals had an EWS in place and encouraged clinical emergency calls to be made to CCO if ward staff were concerned about the status of a deteriorating patient. The remaining hospitals had an EWS and CCO in place. For the seven hospitals that did not have a formalised MET system, the mean percentage of clinical emergencies calls was $4.2 \%$ (range 1-18\%) of referrals to CCO.

One CCO predominantly offered ICU follow-up review, with 95\% of referrals reported as this referral type in this site. Another CCO received most referrals from ward requests (80\%) and had few ICU follow-up reviews (2\%). In all other hospitals the largest proportion of CCO referrals was ward requests for review of acutely unwell patients (mean 53\%, range $27-70 \%$ ). ICU follow-up reviews accounted for a mean value of $35.5 \%$ of CCO referral type (range $23-57 \%$ ). 
Six hospitals provided a training course specific to the recognition and response to deteriorating ward patients: only one was led by CCO. Five hospitals ran nationally/internationally recognised short courses on managing the deteriorating ward patient; these were being delivered by professional development departments. A further hospital had developed a training course locally; this course was designed and delivered by CCO.

Two of the eleven hospitals without CCO provided further commentary describing clinical resource roles that provided support to deteriorating ward patients. One role focused on supplying medication and equipment to wards; the other reported a clinical role for one nurse, responsible for promoting early warning score (EWS) compliance, providing cannulation and venipuncture services, clinical guidance afterhours and policy development.

\section{Staffing and workforce}

There was further variability described in the staffing, workforce and hours of CCO operation. Four hospitals provided a fully staffed CCO 24/7. These teams were operated with 4.2-12 full time nurses (FTE). Three CCO provided limited cover 7 days per week: mornings only, afternoons only, afternoons and evenings using 1.4 2.5 FTE. Two CCO were run out of ICU with no formal CCO establishment, staffed on an ad-hoc basis.

Four CCO were classified as senior nurse roles only, and five CCO had a senior nurse professionally run the service, with the remaining staff at non-senior level. In addition, one CCO offered opportunity for Nurse Practitioner internship within the team. In terms of ICU experience, five CCO reported that every member of staff had ICU experience, three reported most of their staff had ICU experience and one CCO reported less than half their staff as having ICU experience. For CCO staff without ICU experience, their critical care expertise came from working in emergency department, coronary care, high dependency units and acute care wards. Every CCO was funded through the ICU staffing budget.

The CCO were all nurse-led, with professional leadership from senior clinical nurses and managers. Medical support was reported as accessible in over $66 \% \mathrm{CCO}$, with ICU registrars conducting patient reviews, attending clinical emergencies and included in the EWS escalation process. In all these sites, there was an identified ICU Consultant/specialist acting as medical liaison for CCO.

Clinical delivery of care by CCO staff 
In the survey, delivery of care was categorised into clinical activities and clinical interventions. CCO staff were involved in a range of clinical activities and interventions. The most frequently performed clinical activities were supporting ward staff and physical assessment. Some of the least performed activities were those specific to CCO that held a specific function within the hospital e.g. one service provided tracheostomy support for all patients discharged from ICU (Table 3).

INSERT TABLE 3: Most frequently performed clinical activities of CCO

All nine CCO titrated oxygen therapy and 78\% CCO adjusted the frequency of vital signs (Table 4). Notably some of the interventions were related to giving advice to medical staff on changes to medication prescribing, giving clear indication of how CCO work to support local medical teams.

INSERT TABLE 4: Most frequently performed clinical interventions of CCO

Data collection by $\mathrm{CCO}$

Every CCO routinely collected a range of data (Table 5) through both paper \& electronic records.

INSERT TABLE 5: Data routinely collected by CCO

All CCO recorded the date, time, location, referral type and patient details of each visit. Most (89\%) documented the Early Warning Score (EWS), CCO nurse activities and patient outcome. Less than half CCO monitored EWS compliance, unplanned ICU admissions or readmission rates. One hospital had integrated CCO data entry into their hospital-wide clinical database, thereby connecting patient reviews with other patient details (ID, laboratory, radiology, clinical discharge summary, outpatient clinics). All other CCO recorded information about individual patient visits. All CCO provided data reports to their local team/ward and hospital committees. There were no reports of data dissemination between CCO and other hospitals. Three CCO had disseminated data at conferences with one reporting in a Journal publication (Figure 3).

INSERT FIGURE 3: Service level reporting of CCO data 


\section{Discussion}

In reporting on findings from the NZ census of $\mathrm{CCO}$, distinct similarities and differences were revealed with the international literature. The discussion explores three key areas: adoption of CCO; CCO clinical models; and CCO clinical activities.

\section{Adoption of CCO}

The finding that less than half of acute care public hospitals in NZ have a CCO contrasts with the higher incidence (73\%) of CCO reported in the survey of 191 hospitals in England (McDonnell et al., 2007). This reflects quicker adoption of CCO in England than in NZ. The first CCO in England was launched in 1996 with wider uptake of CCO within acute care hospitals from 2000-2002 (McDonnell et al., 2007). A similar Australian study of 113 hospitals reported ICU liaison nurses (ICULN) operated in $27 \%$ of surveyed hospitals (Eliott et al., 2012). ICULN roles were first commenced in $1991(n=1)$, with steady uptake until $2004(n=6)$ and a more rapid launch of services from 2005-2010. (Chaboyer et al., 2004; Eliott et al.,2012).

The reason for the evident peak and leveling out of CCO uptake in NZ public hospitals is unclear and this trend contrasts with the more steady growth of services in Australia. With the small number of public hospitals in NZ, a smaller number of CCO is expected. Of note most CCO in NZ were established after publication of a national report commenting on the need to improve ward based systems for unwell patients (HDC, 2007). This reactive response to sentinel events is reflective of CCO development in other countries. With increasing life expectancy, co-morbidities and more complex healthcare interventions, this will place an associated increased demand for critical care services, and RRS services (Quach et al., 2008). Given this, it is concerning that there has been little recent investment in CCO in NZ. It may be that such demand is being met through the provision of alternate clinical support services and education programs; but this requires further exploration.

\section{CCO clinical models}

Comparison of the CCO models and activities identified in the survey revealed similarities and differences with the international literature. All CCO in NZ were nurse-led and this is in keeping with the English CCO model (McDonnell et al., 2007). Furthermore most $\mathrm{CCO}(\mathrm{n}=7)$ reviewed patients transferred from ICU to the wards; sharing another key feature of the CCO model. There was Intensive Care Specialist and ICU Registrar level support across all CCO in NZ. This collaborative working is similar to how Australian ICULN work (Eliott et al., 2012). These interdisciplinary Australasian models are different to reported unidisciplinary models of CCO in the 
England (Rowan et al., 2008); and may be more reflective of Australasian health care culture.

There was a considerable variation in the size of workforce in each CCO in NZ with only 4 NZ hospitals operating a dedicated CCO 24 hours each day. From the free text comments, it was reported that each CCO was resourced to meet the needs of each hospital within the resource available. Such variation in CCO staffing and hours of operation is similar to findings in previous English and Australian studies (McDonnell et al., 2007; Eliott et al., 2012). As previously commented (Bersten et al., 2009) it would appear that staffing of RRT was hospital site-dependent, relying on local champions, rather than a minimum standard to ensure patient safety and, in the NZ context, meeting the recommendations of an independent health body (HDC, 2007).

Discussion in the literature often supports standardisation of the often termed 'afferent arm' of RRS (Patterson et al., 2011; Prytherch et al., 2010, Howell and Stevens, 2013). However, with regards to the efferent response arm of RRS, the international literature reveals greater diversity of the models and services put in place. It is clear that RRS are tailored to the structure, size and demands of individual hospitals. However, given the diversity in models of CCO throughout NZ, there is need to explore the core structures, resourcing and quality processes that inform CCO service provision.

\section{CCO clinical activities}

In line with findings from Australian and English studies (McDonnell et al., 2007; Green and Edmonds, 2004), NZ CCO delivered a wide range of activities and interventions targeting two main groups of ward patients, namely those acutely unwell or deteriorating ward patients and those following an intensive care admission. The most frequent clinical interventions utilised by NZ CCO were similar to findings in previous work (McDonnell et al., 2007; Pringle et al., 2011). This NZ study demonstrated limited RRT involvement in prescribing, although this has received some exploration in the literature (Pirret, 2008). From this it can be deduced that CCO nurses undertake similar roles and clinical functions internationally.

Findings from the survey demonstrate that whilst NZ CCO predominantly focuses on direct clinical interventions and providing support, there is little involvement in formal education. However higher numbers of CCO in England are engaged in formal education (82.4\%) and informal bedside teaching (77.4\%)(McDonnell et al., 2007). In Australia the role of CCO has improved the liaison between wards and ICU, provided 
support to ward nurses and education about complex interventions (Chaboyer et al., 2005; Athifa et al., 2011): this has enhanced ward based nursing knowledge and skills and facilitated discharges from ICU (Green et al., 2004; Williams et al., 2010). With only one RRT reporting involvement in formal education, this raises concern as to how junior ward based staff in NZ are supported to develop acute care skills. This identifies need for review of how educational needs for doctors and nurses in this area are being met.

Despite a range of clinical data collected by each CCO in this study, there was no consensus at to where this data was reported to, nor how this data was used at a corporate or organizational level. The reliance on paper records and local databases to record CCO data reflected a lack of local infrastructure and resourcing that might otherwise allow for sharing and processing of CCO data sets. Internationally it is recognised that there is difficulty in knowing what data RRS should collect with no agreed international data set (DeVita et al., 2006). Comparison of CCO activation, CCO performance and adverse patient outcomes across hospitals using core data elements recommended in the ILCOR Consensus Statement could lead to clinical outcome improvements (Peberdy et al., 2013) and be used as guidance for all NZ hospitals to improve their systems.

The importance of CCO informing hospital processes and improve patient outcome has been well-recognised. With high profile policy reports (Keogh, 2013) and bodies across UK and Australia (National Institute for Health and Clinical Eexcellance, 2007; ACSQHC, 2011) recommending use of RRT models, this raises questions where national level clinical governance within $\mathrm{NZ}$ is driven from.

Limitations of study

Key limitations of this survey related to the sample size and the maintenance of anonymity. Non-probability sampling was undertaken in approaching all 20 DHBs in NZ. Rural hospitals were not approached and this may be a potential limitation.

Only 11 of the 20 public hospitals across NZ had CCO, thereby further decreasing an already small sample size. Even with the $100 \%$ response rate yielded, this population sample is small compared with sample populations in similar English (139 CCO in 191 hospital sites) and Australian (31 RRS in 113 hospital sites) studies (McDonnell et al, 2007; Eliott et al, 2012). However, results from this study give a clear description of the current knowledge about CCO provision in NZ. With such a small sample, careful attention to maintaining anonymity in the reporting of findings was necessary.

Conclusion 
This study describes the scope and function of CCO in public NZ hospitals. Over half of DHBs within NZ are without an established CCO, despite an advisory health report advising all hospitals to implement a system of care to identify and respond early to deteriorating patients (HDC, 2007). The minority of hospitals that operate a CCO have adapted established international CCO models to fit each local hospital, with minimal regional integration.

Our findings indicate that many remaining NZ hospitals may not currently be able to implement the advisory policy's recommendations due to limited resources or lack of perceived need. The resultant wide variation in CCO practice and in data collection requires a national level response. In recognising the importance that other countries have placed on supporting the acuity agenda, this raises questions as to whether a more proactive response in New Zealand is required. It is hoped that the findings from this study, the first to emerge from NZ, will inform the international literature in this area and raise the profile for future development and evaluation of CCO on patient outcomes within NZ hospitals.

WHAT IS KNOWN ABOUT THIS TOPIC

- CCOS have been introduced internationally, to recognise and respond to acutely unwell ward patients.

- There are several models of CCOS yet no evidence to support which model is most effective.

WHAT THE PAPER ADDS

- Knowledge and understanding of New Zealand CCOS models

- International understanding of the similarities and challenges in providing $\mathrm{CCO}$. 


\section{References}

Athifa M, Finn J, Brearley L, Williams TA, Hay B, Laurie K, Leen T, O'Brien K, Stuart M, Watt M, Leslie G. (2011). A qualitative exploration of nurse's perception of critical outreach service: A before and after study. Australian Critical Care, 24, 39-47.

Australian Commission on Safety and Quality in Health Care (2011). A guide to support implementation of the national consensus statement: essential elements for recognising and responding to clinical deterioration. Sydney, ACSQHC.

Bellomo R, Goldsmith D, Uchino S (2003). A prospective before-and-after trial of a medical emergency team. Medical Journal of Australia, 179, 283-287.

Bersten AD, Soni N, Oh TE. Oh's Intensive Care Manual 6th edition: ButterworthHeinemann, 2009.

Bowen GA. (2009). Document analysis as a qualitative research method. Qualitative Research Journal 9, 2, 27-40.

Buist M, Harrison J, Abaloz E, Van Dyke S. (2007). Six year audit of cardiac arrests and medical emergency team calls in an Australian outer metropolitan teaching hospital. British Medical Journal, 335, 1210-1212.

Chaboyer W, Foster MM, Foser M, Kendall E. (2004). The Intensive Care Unit Liaison Nurse: Towards a clear role description. Intensive and Critical Care Nursing, 20, 7786.

Chaboyer W, Gillespie B, Foster M, Kendall E, James H. (2005). The impact of an ICU Liaison Nurse: A case study of ward nurses' perceptions. Journal of Clinical Nursing, 14, 766-775.

Chan PS, Jain R, Nallmothu BK, Berg RA, Sasson C. (2010). Rapid Response Teams: A systematic review and meta-analysis. Archives of Internal Medicine, 170, (1), 18-26

Coombs, M.A. and Dillon, C.A. (2002) Crossing boundaries, re-defining care: the Critical Care Outreach team. Journal of Clinical Nursing, 11, (3), 387-393

Department of Health (2005). Quality critical care. Beyond 'comprehensive critical care.' London. 
DeVita MA, Bellomo R, Hillman K, Kellum J, Rotondi A, Teres D et al., (2006). Findings of the first consensus conference on medical emergency teams. Critical Care Medicine, 34 (9), 2463-2478.

Donohue L A, \& Endacott R. (2010). Track, trigger and teamwork: Communication of deterioration in acute medical and surgical wards. Intensive and Critical Care Nursing, 26, 10-17.

Eliott S, Chaboyer W, Ernest D, Doric A, Endacott R. (2012). A national survey of Australian Intensive Care Unit (ICU) Liaison Nurse (LN) services. Australian Critical Care, 25, 253-262.

Elo S, Kyngäs H (2008). The qualitative content analysis process. Journal of Advanced Nursing 62, 1, 107-115.

Esmonde L, McDonnell A, Ball C, Waskett C, Morgan R, Rashidian A et al. (2006). Investigating the effectiveness of critical care outreach services: a systematic review. Intensive Care Medicine 32, 1713-1721.

Francis R. (2013). Report of the Mid Staffordshire NHS Foundation Trust Public Inquiry: Executive Summary. Available from :

http://www.midstaffspublicinquiry.com/sites/default/files/report/Executive\%20sum mary.pdf [Accessed 15 ${ }^{\text {th }}$ August 2013]

Green A, Edmonds L. (2004). Bridging the gap between the intensive care unit and general wards - the ICU liaison nurse. Intensive and critical care nursing. 20,133143.

Health and Disability Commissioner. (2007). A report by the Health and Disability Commissioner into "Patient $A$ " [Internet]. Available from: http://www.hdc.org.nz/decisions--case-notes/commissioner'sdecisions/2007/05hdc11908. [Accessed 10th August 2013]

Hillman K, Chen J, Cretikos M, Bellomo R, Brown D, Doig G, Finfer S, Flabouris A. (2005). Introduction of the Medical Emergency Team (MET) system: a clusterrandomised controlled trial. Lancet 365, 2091-2097. 
Hillman K, Parr M, Flabouris A, Bishop G, Stewart A. (2001). Redefining in-hospital resuscitation: the concept of the medical emergency team. Resuscitation 48 (2), 105 -110 .

Howell MD, Stevens JP. (2013). Rapid Response Systems. [Internet]. Available from: http://www.uptodate.com/contents/rapid-responsesystems?topicKey=PC/16280\&elapsedTimeMs=3\&view=print \&displayedView=full [Accessed $12^{\text {th }}$ September 2014].

Jones D, Bates S, Warrilow S. (2005). Long term effect of a medical emergency team on cardiac arrests in a teaching hospital. Critical Care, 9, R808-815.

Jones DA, Devita MA, Bellomo R. (2011). Rapid Response teams. New England Journal of Medicine, 365 (2), $139-146$.

Jones D, Mitchell I, Hillman K, Story D. (2013). Defining clinical deterioration. Resuscitation, 84, 1029-1034.

Keogh B. (2013). Review into the quality of care and treatment provided by 14 hospital trusts in England: an overview report. Available from:

http://www.nhs.uk/NHSEngland/bruce-keogh-review/Documents/outcomes/keoghreview-final-report.pdf [Accessed 15th August 2013]

McDonnell A, Esmonde L, Morgan R, Brown R, Bray K, Parry G, Adam S, Sinclair R, Harvey S, Mays N, Rowan K. (2007). The provision of critical care outreach services in England: findings from a national survey. Journal of Critical Care, 22, 212-218.

National Institute for Health and Clinical Excellence (NICE). (2007). Acutely ill patients: recognition of and response to acute illness in adult hospitals. NICE clinical guideline No.50.

Patterson c, Maclean F, Bell C et al. (2011). Early Warning systems in the UK: Variation in content and implementation strategy has implications for a NHS early warning system. Clinical Medicine, 11, 424-427.

Peberdy MA, Cretikos M, Abella BS, DeVita M, Goldhill D, Kloeck W, Kronick SL, Morrison $\amalg$, Nadkarni VM, Nichol G, Nolan JP, Parr M, Tibballs J, van der Jagt EW, Young L. (2013). Recommended guidelines for monitoring, reporting, and conducting research on medical emergency team, outreach, and rapid response systems: An Utstein-style scientific statement. Circulation, 116, 2481 - 2500. 
Pirret AM. (2008). The role and effectiveness of a nurse practitioner led critical care outreach service. Intensive and Critical Care Nursing, 24, 375-382.

Pringle R, Hanson C, Falk NL. (2011). Literature review on rapid response systems. Nursing Alliance for Quality Care. Available from: https://nursing.gwu.edu/sites/nursing.gwu.edu/files/downloads/Rapid Response T eam Literature Review 2-28-2011.pdf [Accessed 23rd September 2013]

Prytherch DR, Smith GB, Schmidt PE, Featherstone PI. (2010). ViEWS - Towards a national early warning score for detecting adult inpatient deterioration.

Resuscitation, 81, 932-937.

Psirides A, Hill J, Hurford S. (2013). A review of rapid response team activation parameters in New Zealand hospitals. Resuscitation

Rattray J. (2007). Essential elements of questionnaire design and development. Journal of Clinical Nursing, 16, (2), 234-243.

Quach JL, Downey AW, Haase M et al. (2008). Characteristics and outcomes of patients receiving a medical emergency team review for respiratory distress or hypotension. Journal of Critical Care, 23 (3), 325-331.

Resuscitation Central (2013). Rapid response and medical emergency teams. Available from: (http://www.resuscitationcentral.com/documentation/rapidresponse-medical-emergency-team/ [Accessed 23 ${ }^{\text {rd }}$ September 2013]Rowan K et al, (2008) Evaluation of outreach services in critical care: Project SDO/74/2004. Available from: http://www.netscc.ac.uk/hsdr/files/project/SDO FR 08-1404074 V01.pdf [Accessed 20th July 2013]

Salt L. (2013). Evaluating critical car outreach and the early warning score tool - the ward nurse's viewpoint. Kai Tiaki Nursing Research, 4, 17-23.

Steel AC, Reynolds SF. (2008). The growth of rapid response systems. Joint Commission Journal of Quality and Patient Safety, 34, 489-495. 
Williams TA, Leslie G, Finn J, Brearley L, Athifa M, Laurie K et al. (2010). Clinical effectiveness of a Critical Care Nursing Outreach Service in facilitating discharge from the Intensive Care Unit. American Journal of Critical Care, 19, e63-72.

Winters BD, Pham JC, Hunt EA, Guallar E, Berenholtz S, Pronovost PJ. (2007). Rapid response systems: A systematic review. Critical Care Medicine, 35, (5), 1238-1243.

Winters BD, Weaver SJ, Pfoh ER, Yang T, Pham JC \& Dy SM. (2013). Rapid-Response Systems as a Patient Safety Strategy: A Systematic Review. Annals of Internal Medicine, 158 (5), 417-425. 
Demographic information about each hospital Clinical delivery of care (activities and interventions) Documentation

Staffing and workforce of each CCO

Medical support for $\mathrm{CCO}$

Data collection

Process improvement initiatives

Table 1: Overview of topics included in the census

\begin{tabular}{|l|r|l|l|}
\hline Hospital type & $\begin{array}{l}\text { No. eligible } \\
\text { sites }\end{array}$ & $\begin{array}{l}\text { No. of sites with CCO } \\
\text { (Stage 1) }\end{array}$ & $\begin{array}{l}\text { No. CCO that provided } \\
\text { clinical documents } \\
\text { (Stage 2) }\end{array}$ \\
\hline Tertiary & 5 & 4 & 4 \\
\hline Metropolitan \& regional & 15 & 5 & 4 \\
\hline Total & 20 & 9 & 8 \\
\hline
\end{tabular}

Table 2: Hospital eligibility for data collection 


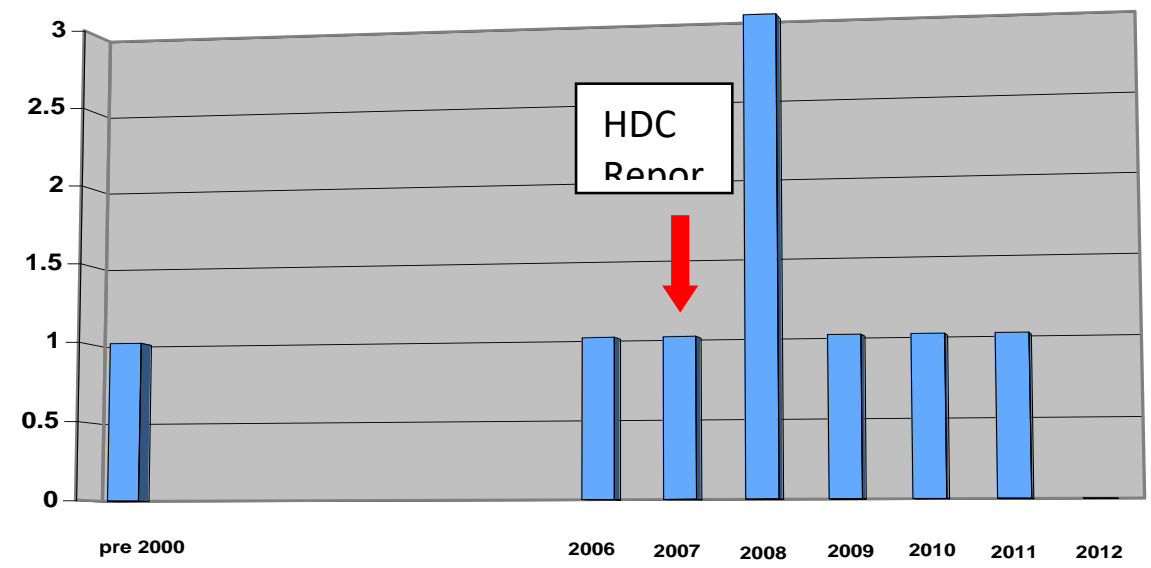

Figure 1: Year of establishment of CCO

\begin{tabular}{|l|rr|}
\hline Activity of CCO & Number of CCO performing \\
& activity \\
\hline Support to ward staff & 8 & $(88.9 \%)$ \\
\hline Physical assessment & 7 & $(77.8 \%)$ \\
\hline Clinical support to patients & 7 & $(77.8 \%)$ \\
\hline Advice and intervention in support of primary team & 7 & $(77.8 \%)$ \\
\hline Advice only & 5 & $(55.6 \%)$ \\
\hline Support to patient/family & 3 & $(33.3 \%)$ \\
\hline Informal bedside teaching & 3 & $(33.3 \%)$ \\
\hline Formal educational courses & 1 & $(11.1 \%)$ \\
\hline
\end{tabular}




\begin{tabular}{|l|r|}
\hline Tracheostomy review & 1 (11.1\%) \\
\hline Referral to another service/therapist & 1 (11.1\%) \\
\hline Locating and/or problem-solving equipment & 1 (11.1\%) \\
\hline Telephone advice & 1 (11.1\%) \\
\hline
\end{tabular}

Table 3: Most frequently performed clinical activities of CCO

\begin{tabular}{|l|r|}
\hline Intervention of CCO & $\begin{array}{l}\text { Number of CCO performing } \\
\text { intervention }\end{array}$ \\
\hline Changes in oxygen therapy * & $9(100 \%)$ \\
\hline Adjust frequency of vital signs & $7(77.8 \%)$ \\
\hline Changes in patient position & $6(66.7 \%)$ \\
\hline Changes in fluid management * & $6(66.7 \%)$ \\
\hline Investigations & $6(66.7 \%)$ \\
\hline Insertion of intravenous access & $4(44.4 \%)$ \\
\hline Adjustment to medications e.g. diuretics * & $3(33.3 \%)$ \\
\hline Transfer of patients within hospital & $2(22.2 \%)$ \\
\hline Initiation of non-invasive ventilation (CPAP, BiPAP) * & $1(11.1 \%)$ \\
\hline Insertion of urinary catheter & $1(11.1 \%)$ \\
\hline
\end{tabular}

Table 4: Most frequently performed clinical interventions of CCO

Key: * advice to medical staff on prescription changes

\begin{tabular}{|l|r|}
\hline Data collected & $\begin{array}{l}\text { Number of CCO } \\
\text { collecting data }\end{array}$ \\
\hline Clinical activities of outreach service & $8(88.9 \%)$ \\
\hline Number of cardiac arrests & $7(77.8 \%)$ \\
\hline Number of medical emergency team calls & $6(66.7 \%)$ \\
\hline Early Warning Score chart compliance & $5(55.6 \%)$ \\
\hline Patient outcomes & $3(33.3 \%)$ \\
\hline Number of unplanned ICU admissions & $3(33.3 \%)$ \\
\hline Number of missed MET calls & $1(11.1 \%)$ \\
\hline
\end{tabular}




\begin{tabular}{|l|l|}
\hline Educational & $1(11.1 \%)$ \\
\hline
\end{tabular}

Table 5: Data routinely collected by CCO

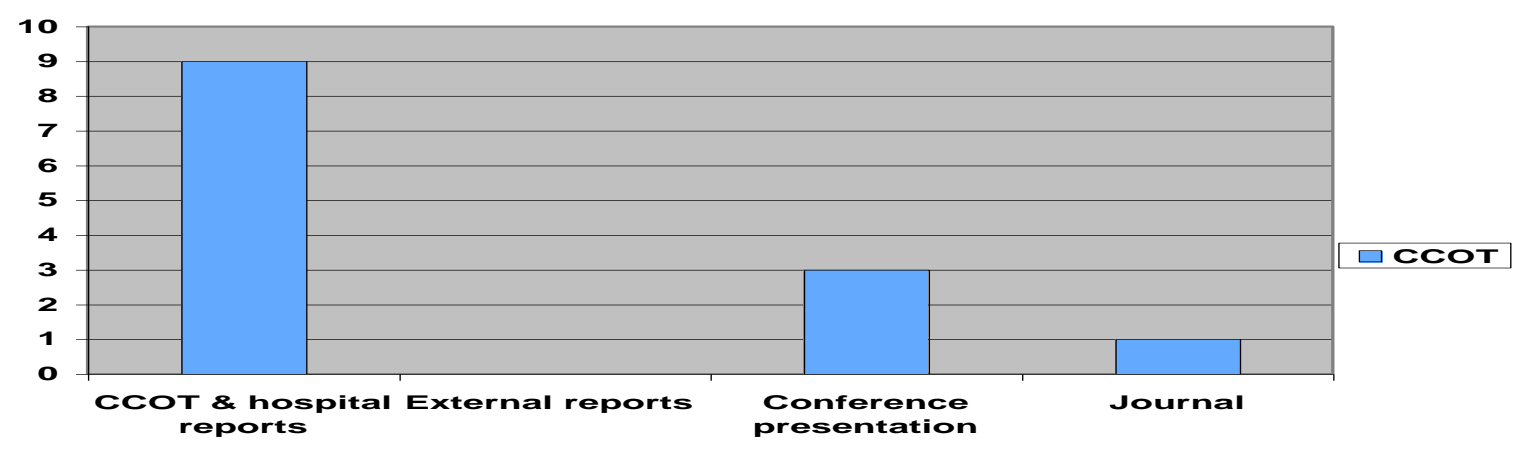

Figure 3: Service level reporting of CCO data 